\title{
Is employment status in adults over 25 years old associated with nonmedical prescription opioid and stimulant use?
}

\author{
Alexander S. Perlmutter ${ }^{1,2} \cdot$ Sarah C. Conner ${ }^{3}$ Mirko Savone $^{1,4}$. \\ June H. Kim ${ }^{1} \cdot$ Luis E. Segura $^{1} \cdot$ Silvia S. Martins ${ }^{1}$
}

Received: 27 July 2016/Accepted: 11 November 2016/Published online: 17 November 2016

(C) Springer-Verlag Berlin Heidelberg 2016

\begin{abstract}
Purpose Nonmedical use of prescription opioid and stimulants (NMUPO and NMUPS, respectively) has declined in recent years, but remains an important public health problem. Evidence regarding their relationships with employment status remains unclear. We determined the relationship between employment status and NMUPO and NMUPS.

Methods We analyzed a cross-sectional, nationally representative, weighted sample of 58,486 adults, ages 26 years and older, using combined 2011-2013 data from the National Survey on Drug Use and Health (NSDUH). We fit two crude and two adjusted multivariable logistic regression models to assess the relationship between our two different outcomes of interest: (1) past-year NMUPO and (2) past-year NMUPS, and our exposure of interest: employment status, categorized as (1) full time, (2) part time, (3) unemployed, and (4) not in the workforce. Our adjusted models featured the following covariates: sex,
\end{abstract}

Alexander S. Perlmutter

alexander.perlmutter@etu.parisdescartes.fr

1 Department of Epidemiology, Columbia University Mailman School of Public Health, 722 168th St., Rm. 518, New York, NY 10032, USA

2 Centre de Recherche Épidémiologie et Statistique Sorbonne Paris Cité UMR1153, Université Paris Descartes, Hôpital Hôtel-Dieu, 1 place du Parvis Notre-Dame, 75004 Paris, France

3 Boston University School of Public Health, 715 Albany St, Boston, MA 02118, USA

4 Department of Pediatric Hematology, Oncology and Stem Cell Transplantation, Columbia University Medical Center, 161 Ft. Washington Avenue IP7, New York, NY 10032, USA race, age, marital status, and psychological distress, and other nonmedical use.

Results Prevalence of NMUPO was higher than NMUPS (3.48 vs. $0.72 \%$ ). Unemployed participants had the highest odds of NMUPO [aOR 1.45, 95\% CI (1.15-1.82)], while those not in the workforce had the highest odds of NMUPS [aOR 1.71, 95\% CI (1.22-2.37)]. Additionally, part-time and unemployed individuals had increased odds of NMUPS [aORs, 95\% CI 1.59 (1.09-2.31) and 1.67 (1.11-2.37) respectively], while those not in the workforce had decreased odds of NMUPO [aOR 0.82, 95\% CI (0.68-0.99)] relative to full-time participants.

Conclusions There is a need for adult prevention and deterrence programs that target nonmedical prescription drug use, especially among those unemployed or not in the workforce.

Keywords Opioid · Stimulant · Nonmedical prescription drug use $\cdot$ Employment $\cdot$ Epidemiology

$\begin{array}{ll}\text { Abbreviations } \\ \text { ADHD } & \text { Attention-deficit hyperactivity disorder } \\ \text { NMPD } & \text { Nonmedical prescription drug(s) } \\ \text { NMUPO } & \text { Nonmedical prescription opioid use } \\ \text { NMUPS } & \text { Nonmedical prescription stimulant use } \\ \text { NSDUH } & \text { National Survey on Drug Use and Health } \\ \text { PDMP(s) } & \text { Prescription Drug Monitoring Program(s) } \\ \text { US } & \text { United States }\end{array}$

\section{Introduction}

Nonmedical prescription drug (NMPD) use, particularly nonmedical use of prescription opioids (NMUPO), has declined in recent years, yet is still an important public 
health problem in the US [1]. Recent literature cites an overall trend in increasing deaths from prescription drugs and heroin [2,3], but decreasing deaths from all other illicit drug use [4-7]. Nonmedical prescription drug use has a profound impact on economic productivity, criminal justice costs, drug use disorder treatment, and medical complications [8]. Further, unintended consequences like the recent increase in heroin use may be attributed partially to NMUPO [9]. In 2006, NMUPO alone cost the United States (US) about $\$ 42$ billion in lost productivity, $\$ 8.2$ billion in criminal justice costs, and $\$ 1$ billion in medical complications [8].

In general, NMPD use has been mostly examined among youth and young adult populations. For example, longitudinal data of high school seniors show that while most NMUPO was transient, approximately one-third of users continued use past the age of 18 years and were consequently at higher odds of developing substance use behaviors, especially recent binge drinking and past-year marijuana and other NMPD use [10]. In a different crosssectional studies, Martins and colleagues found that compared to young adults (18-22 years old) enrolled in college, 18- to 22-year-old people not enrolled were significantly more likely to endorse NMUPO and less likely to endorse nonmedical prescription stimulants (NMUPS) [11]. Relevant to Martins' findings is research showing that earlier entries into adult roles (e.g., foregoing university enrollment to enter the workforce) may be detrimental to individuals who are not well prepared for them [12]. However, some evidence demonstrates that employment is associated with decreased misuse of prescription drugs, as is the case among government employees and those whose employers had a drug-free workplace policy [13].

While this previous research is useful in understanding trends of NMPD use, the lens is on early initiation, which is less helpful for identifying characteristics in adult populations. For instance, while many factors may explain the rise in NMUPO among those not enrolled in college, it is unclear how this translates to employment status. Miller and colleagues observed that employment is protective for NMUPO for those 18-25 years old, but there remains the question of attribution of co-occurring adult roles on substance use decreases past that age period [13]. Smith and Farah reveal that research exploring employment's relationship with NUMPS has been scarce among young adult and older working populations [14]. For instance, prescription stimulants, which are commonly used to control childhood (attention-deficit hyperactivity disorder) ADHD and narcolepsy, are increasingly used in adulthood to control persistent symptoms from childhood [15], which are associated with difficulty in obtaining and keeping fulltime employment. On the other hand, NMUPS has also been on the rise among employed adults, mainly due to desires to improve performance, increase productivity, remain competitive with one's peers [16, 17], or for memory improvement among older adults.

While the deleterious consequences of NMPD use have been researched extensively, less focus has been paid to identifying social characteristics that influence and are influenced by NMPD use. We view the most powerful intervening forces associated with both the labor market and NMPD use to be federal and state regulations, some of which may mandate specific clinical practices. By examining the associations between NMPD use and employment, we can identify groups in which NMPD use is overrepresented and, consequently, recommend regulatory and clinical interventions that would improve users' lives. Thus, the goals of this study were to explore how NMUPO and NMUPS vary by employment status among US adults. We aimed to compare the prevalence and odds of past-year NMUPO and NMUPS among full-time workers with part-time employed, unemployed, and those not in the workforce, adjusting for age, sex, race, past-year psychological distress, marital status, and the NMPD use not being modeled (i.e., adjusting for NMUPO in the case we were modeling NMUPS and vice versa).

\section{Materials and methods}

\section{Study sample and measures}

We analyzed data from 58,486 adults ages 26 years and older from the 2011 ( $n=58,397), 2012(n=55,268)$, and $2013(n=55,160)$ NSDUH public use files. Three consecutive NSDUH years were combined to increase the sample size, as prevalence estimates of NMUPO and NMUPS are low. Respondents are not sampled twice. The NSDUH is an annual cross-sectional survey sponsored by the Substance Abuse and Mental Health Administration [18] and is designed to provide estimates of the prevalence of drug use and disorders in the household population of the US among those 12 years and older. All respondents provided information about their drug experiences and socio-demographic characteristics. The NSDUH questionnaire instrument has sensitivity values ranging from 0.8 to 0.97 for most substances, and specificity values ranging from 0.7 to 0.95 [19].

\section{Outcome variables}

Outcomes of interest: (1) past-year nonmedical prescription opioid use and (2) past-year nonmedical prescription stimulant use. 
Nonmedical use of prescription opioids and prescription stimulants

NMUPO was defined as any self-reported use of prescription pain relievers that were not prescribed for the respondent or that the respondent took only for the experience or feeling they caused [20]. All respondents were given the following instructions: "These questions are about prescription pain reliever use. We are not interested in your use of over-the-counter pain relievers that can be bought in stores without a doctor's prescription." The NSDUH used a similar screening question that assessed whether the respondent had ever used a core prescription stimulant that was not prescribed or taken for the experience or feeling it caused [18]. Pastyear NMUPO and NMUPS were recorded based on responses to questions asking how much time had passed since last NMUPO and NMUPS, respectively. These groups are not mutually exclusive, thus an individual could self-report both past-year NMUPO and past-year NMUPS.

\section{Primary exposure variable}

Current employment status is classified in the NSDUH as: (1) employed full time (at least $35 \mathrm{~h}$ per week), (2) employed part time (less than $35 \mathrm{~h}$ per week), (3) unemployed (no job or layoff, but looking for work), and (4) not in the workforce. Individuals "not in the workforce" are not actively seeking work, which includes retirees, disabled persons, homemakers, students, and those who have given up on attaining employment.

\section{Demographic covariates}

Demographic variables selected for this study included sex, age, race (non-hispanic white, combined non-white races), and marital status. Some of these covariates, which are proxies for social maturity (i.e., advanced age and marriage), in addition to white race, male sex [13], and psychological distress, may affect the strength of the relationship between the outcomes and employment status. Due to small sample sizes and similar use patterns within racial/ethnic groups, plus the appreciably higher prevalence and frequency of prescription drug use within the white racial group [11], we chose to combine non-white races into a single category. We chose not to include education in our analysis due to sample size constraints and the presence of our main exposure variable, employment, a variable strongly predicted by education. Additionally, marital status was dichotomized due to similar use patterns among non-married subgroups, including divorced, separated, and widowed respondents.
This study only included adults aged 26 years and older because of our focus on the adult workforce; therefore we excluded young adults who were still completing their studies. Restricting our population to this age group sheds light on a previously understudied relationship between employment status and nonmedical prescription drug-using populations over 25 years [21].

\section{Past-year psychological distress}

We also adjusted for the presence of psychological distress, since several studies have shown its association with NMUPO [22, 23]. Weyandt and colleagues list the body of literature demonstrating the association between NMUPS and depression, anxiety, stress, and internal restlessness [24]. Serious psychological distress was measured using the Kessler 6 (K6) screening instrument for non-specific psychological distress. The tool consists of six items, each with a 0-to-4-point rating scale that screens for general distress in the past year (Cronbach's $\alpha=0.89$ ).

\section{Other use}

We controlled for the effect of NMUPS on the association between employment status and NMUPO. Similarly, we controlled for the effect of NMUPO on the association between employment status and NMUPS.

\section{Statistical analyses}

Data were weighted to reflect the complex design of the NSDUH sample and were analyzed using SAS 9.4 (SAS Institute, Cary, NC, USA). We used Taylor series estimation methods to obtain proper standard error estimates for the Chi-square cross-tabulations and logistic regressions. All percentages reported are weighted by study weights. Logistic regressions estimated the log odds of NMUPO and NMUPS. All adjusted log odds of NMUPO and NMUPS were controlled for sex, age, race, and marital status, pastyear psychological distress, and past-year use of the drug that was not modeled.

\section{Results}

\section{Prevalence of past-year NMUPO and NMUPS by employment status (Table 1)}

Past-year prevalence of NMUPO and NMUPS were 3.48 and $0.72 \%$, respectively. Among those unemployed, 6.91 and $1.70 \%$ were NMUPO and NMUPS, respectively, the highest prevalences within any employment status. Among those employed full time, $3.84 \%$ were NMUPO and $0.64 \%$ 
Table 1 Past-year prevalence of nonmedical prescription opioid and stimulant use among adults aged 26 years and older; data from National Survey on Drug Use and Health (NSDUH), 2011-2013

\begin{tabular}{|c|c|c|c|c|c|c|c|c|}
\hline \multirow[t]{2}{*}{ Socio-demographic characteristics } & \multicolumn{2}{|l|}{ Overall } & \multicolumn{3}{|c|}{ NMUPS } & \multicolumn{3}{|c|}{ NMUPO } \\
\hline & $N^{\mathrm{a}}$ & $\%^{\mathrm{b}}$ & $N^{\mathrm{a}}$ & $\%^{\mathrm{b}}$ & $\chi^{2} p$ value & $N^{\mathrm{a}}$ & $\%^{\mathrm{b}}$ & $\chi^{2} p$ value \\
\hline Overall & 58486 & & 512 & 0.72 & & 2485 & 3.48 & \\
\hline Employment & & & & & $<0.0001 *$ & & & $<0.0001 *$ \\
\hline Full time & 32512 & 51.99 & 257 & 0.64 & & 1398 & 3.84 & \\
\hline Part time & 7320 & 11.75 & 74 & 0.99 & & 317 & 3.77 & \\
\hline Unemployed & 3067 & 4.35 & 60 & 1.70 & & 247 & 6.91 & \\
\hline Other & 15587 & 31.90 & 121 & 0.62 & & 523 & 2.34 & \\
\hline Age (years) & & & & & $<0.0001^{*}$ & & & $<0.0001^{*}$ \\
\hline $26-34$ & 16564 & 18.4 & 308 & 2.11 & & 1203 & 7.42 & \\
\hline $35-49$ & 22521 & 30.42 & 156 & 0.68 & & 944 & 4.12 & \\
\hline $50+$ & 19401 & 51.18 & 48 & 0.25 & & 338 & 1.70 & \\
\hline $\operatorname{Sex}$ & & & & & 0.19 & & & $0.0004 *$ \\
\hline Female & 31786 & 52.22 & 257 & 0.66 & & 1180 & 3.06 & \\
\hline Male & 26700 & 47.78 & 255 & 0.79 & & 1305 & 3.95 & \\
\hline$R a c e^{c}$ & & & & & $0.0055^{*}$ & & & 0.3229 \\
\hline White & 38645 & 67.96 & 380 & 0.81 & & 1719 & 3.55 & \\
\hline Non-white combined & 19841 & 32.04 & 132 & 0.53 & & 766 & 3.35 & \\
\hline Psychological distress & & & & & $<0.0001 *$ & & & $<0.0001^{*}$ \\
\hline No & 52046 & 90.63 & 331 & 0.52 & & 1770 & 2.81 & \\
\hline Yes & 6440 & 9.37 & 181 & 2.63 & & 715 & 10.05 & \\
\hline Marital status ${ }^{d}$ & & & & & $<0.0001^{*}$ & & & $<0.0001^{*}$ \\
\hline Unmarried & 25358 & 40.14 & 365 & 1.25 & & 1506 & 4.86 & \\
\hline Married & 33128 & 59.86 & 147 & 0.36 & & 979 & 2.57 & \\
\hline \multicolumn{9}{|l|}{$* p$ value $<0.05$} \\
\hline \multirow{2}{*}{\multicolumn{9}{|c|}{$\begin{array}{l}\text { a Frequencies are unweighted and proportions are weighted } \\
\text { b Proportions listed are conditional probabilities of each outcome given the socio-demographic } \\
\text { characteristic }\end{array}$}} \\
\hline & & & & & & & & \\
\hline \multicolumn{9}{|c|}{$\begin{array}{l}{ }^{c} \text { Due to high prevalence of prescription drug use among white participants and low prevalence among } \\
\text { black, Hispanic, Asian, and other races, race was dichotomized into white and non-white }\end{array}$} \\
\hline
\end{tabular}

were NMUPS. Among those employed part time, 3.77\% were NMUPO and $1 \%$ were NMUPS. Lastly, among those not in the workforce, $2.34 \%$ were NMUPO and $0.62 \%$ were NMUPS (Table 1). A large plurality of those not in the workforce were those over 65 years old.

\section{Adjusted odds of NMUPO and NMUPS by employment status (Table 2)}

The adjusted odds of each outcome by employment status varied significantly. Unemployed respondents had increased odds of NMUPO [aOR $1.45,95 \%$ CI (1.15-1.82)] and of NMUPS [aOR 1.67, 95\% CI (1.11-2.51)] compared to those employed full time. Individuals not in the workforce [aOR 1.71, 95\% CI (1.22-2.37)] and part-time employees [aOR 1.59, 95\% CI (1.09-2.31)] were more likely to endorse past-year
NMUPS than their full-time counterparts. Individuals not in the workforce were $18 \%$ less likely to endorse NMUPO [aOR 0.82, 95\% CI (0.68-0.99)].

\section{Adjusted odds of NMUPO and NMUPS by demographics, and social and behavioral attributes (Table 2)}

Adjusting for all covariates, males were 1.35 times more likely to endorse NMUPO than females [aOR 1.35, 95\% CI (1.14-1.59)], while the odds ratio of NMUPS by sex was not significant. Non-whites were less likely to endorse NMUPO [aOR 0.80, 95\% CI (0.69-0.92)] and NMUPS [aOR $0.54,95 \%$ CI (0.39-0.75)] than non-hispanic whites. Individuals aged 35-49 years were less likely than those aged 26-34 years to endorse NMUPO [aOR $0.65,95 \% \mathrm{CI}$ (0.57-0.74)] and NMUPS [aOR 0.46, 95\% CI (0.35-0.59)], 
Table 2 Crude and adjusted odds of past-year nonmedical prescription opioid and stimulant use among adults aged 26 years and older; data from the National Survey on Drug Use and Health (NSDUH), 2011-2013

\begin{tabular}{|c|c|c|c|c|}
\hline \multirow[t]{2}{*}{ Unadjusted model } & \multicolumn{2}{|c|}{ NMUPS } & \multicolumn{2}{|c|}{ NMUPO } \\
\hline & OR & $95 \% \mathrm{CI}$ & OR & $95 \% \mathrm{CI}$ \\
\hline
\end{tabular}

\begin{tabular}{lllll}
\hline Employment status & & & & \\
Full time & - & - & - & - \\
Part time & $1.56^{*}$ & $1.07-2.26$ & 0.98 & $0.81-1.19$ \\
Unemployment & $2.70^{*}$ & $1.84-3.95$ & $1.86^{*}$ & $1.51-2.29$ \\
Other & 0.98 & $0.73-1.31$ & $0.60^{*}$ & $0.50-0.72$ \\
\hline Adjusted model & aOR & $95 \% \mathrm{CI}$ & aOR & $95 \% \mathrm{CI}$ \\
\hline
\end{tabular}

\section{Employment status}

Full time

Part time

Unemployment

Other

$1.59 *$

$1.59 * \quad 1.09-2.31 \quad 1.02$

$0.84-1.24$

$1.67 * 1.11-2.51 \quad 1.45^{*}$

$1.15-1.82$

Age (years)

26-34

$35-49$

$50+$

$1.71 * \quad 1.22-2.37 \quad 0.82 *$

$0.68-0.99$

Sex

Female

Male

Race $^{\mathrm{b}}$

White

Non-white combined

Psychological distress

No

Yes

Marital status ${ }^{\mathrm{c}}$

Unmarried

Married

Past-year use of NMUPO

Past-year use of NMUPS

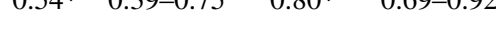$$
\begin{array}{llll}
- & - & - & - \\
2.24 * & 1.66-3.03 & 2.94 * & 2.55-3.39
\end{array}
$$$$
\text { (1.66-3.03 } 2.94 * 0.2 .55
$$$$
\begin{array}{llll}
0.45 * & 0.34-0.60 & 0.66 * & 0.58-0.75
\end{array}
$$$$
9.77 * 7.49-12.73-
$$

$\begin{array}{llll}- & - & - & - \\ 0.46 * & 0.35-0.59 & 0.65 * & 0.57-0.74 \\ 0.17 * & 0.12-0.25 & 0.30 * & 0.25-0.36\end{array}$

$$
\begin{array}{llll}
- & - & - & - \\
1.22 & 0.90-1.69 & 1.35^{*} & 1.14-1.59
\end{array}
$$$$
\begin{array}{llll}
- & - & - & - \\
0.54 * & 0.39-0.75 & 0.80 * & 0.69-0.92
\end{array}
$$

$10.16^{*} \quad 7.91-13.04$

$* p$ value $<0.05$

${ }^{a}$ Due to high prevalence of prescription drug use among white participants and low prevalence among black, Hispanic, Asian, and other races, race was dichotomized into white and non-white

b Divorced, widowed, and separated individuals were included in this category since no significant differences were observable between these subgroups

while those ages 50 years and older were between three and six times less likely to endorse NMUPO [aOR 0.30, 95\% CI (0.25-0.36)] and NMUPS [aOR 0.17, 95\% CI $(0.12-0.25)]$ than those aged 26-34 years. Married respondents were less likely than unmarried respondents to endorse NMUPO [aOR 0.66, 95\% CI (0.58-0.75)] and NMUPS [aOR 0.45, 95\% CI (0.34-0.60)], and those endorsing past-year psychological distress were about three times more likely to endorse NMUPO [aOR 2.94, 95\% CI (2.55-3.39)] and slightly less likely to endorse NMUPS [aOR 2.24, 95\% CI (1.66-3.03)] than those without psychological distress.

\section{Adjusted odds of other use (Table 2)}

Not controlling for other use would have overestimated the associations between employment status and NMUPO/ NMUPS. After controlling for other use, we observed that those endorsing past-year NMUPO were ten times more likely to endorse NMUPS [aOR 9.77, 95\% CI (7.49-12.73)] than those without NMUPO. Similarly, those endorsing past-year NMUPS were also ten times more likely to endorse NMUPO [aOR 10.16, 95\% CI (7.91-13.04)] than those without NMUPS.

\section{Discussion}

Our analysis indicated higher odds of NMUPO among the unemployed and $18 \%$ lower odds of NMUPO among those not in the labor force, compared with those who were employed full time. The data also showed higher odds of NMUPS among all non-full-time employed groups compared with those employed full time, despite the fact that drug use and drug use disorder are highly prevalent among full-time employed people [25]. Our findings on these associations parallel other research on engaging in adult roles, such as marriage and parenthood [26].

Additionally, our findings on the inverse relationship between increasing age range among adults aged 26 years and older (i.e., from $26-34$ to $35-49$ to $50+$ ) and the decreasing odds of NMUPO and NMUPS confirm the results from the Monitoring the Future study [27]. While it has been shown that those who use illegal and prescription drugs may decrease their usage with the onset of other adult roles (i.e., marriage, parenthood, full-time employment, etc.) [28], drug misuse remains common in adults under 50 years, and nonmedical use prevention strategies tailored to particular age groups must be considered. For instance, though abuse risks are lower in older chronic pain patients [29], clinicians have adopted a Universal Precautions approach to pain management whereby patients are assessed for risk factors related to problematic use of pain medication [29]. Our finding that not being in the labor force (e.g., retired) is protective of NMUPO could mean that clinical precautions are working. We observed a positive association between those not in the labor force and NMUPS. This could be partially attributable to those not in the labor force (e.g., retired) irresponsibly using cognitive enhancers to improve memory [30]. Similar actions (i.e., 
clinical and regulatory) may be in order to educate stimulant users to prevent stimulant diversion among those not in the labor force.

Unemployed NSDUH respondents had higher odds of both NMUPO and NMUPS than their full-time counterparts. Unemployment and its correlates are associated with health issues from cardiovascular disease to mental disorders. A Danish study showed that men on unemployment benefits were $1.50,1.28$, and 2.00 times more likely to have diabetes, cancer, and mental disorders, respectively, than employed men. Other social benefit statuses, means-tested cash-benefit and disability pensions (both may be considered unemployed statuses in the US), were associated with a much higher disease incidence [31]. Another study demonstrated that unemployment was associated with completed suicides, a figure that inflates among those with financial problems [32]. The observation that unemployment is associated with a host of diseases, particularly mental disorders (which we also found), is a strong caution for those instituting policies regulating NMPD control. Physicians should be aware of patients' employment status and the elevated risk between unemployment and nonmedical drug use and drug and mental disorders prior to prescribing. Aside from prescription drug monitoring programs (PDMPs), which assist prescribers, an increased layer of precaution should include a physician requirement to assess abuse potential, specifically of unemployed patients.

We lastly found that part-time employment and psychological morbidity are positively associated with NMUPO. Studies show that people struggling with psychological distress and concurrent NMPD use are less likely to attain and maintain full-time employment, which may leave them in part-time or temporary employment (i.e., precarious employment) [33, 34].

The associations between employment status, NMUPO, and NMUPS yield important public health implications. By improving our understanding of these associations and the role of employment in drug use behaviors and modes of access, drug prevention and deterrence programs can target users more effectively, especially when combined with regulation. It is imperative that interventions are sensitive to non-full-time employed people, a population that our data suggests is one with greater social disadvantage. Nonfull-time employed people may suffer disproportionately from the indirect harms of NMUPO and NMUPS insomuch that they have less income, less wealth, and perhaps, less dynamic social support structures [35, 36], such as family-, neighborhood-, and community-level social ties that would help mitigate harms related to misuse. While this population would clearly benefit from targeted prevention and deterrence, policy measures like withholding social benefits due to a positive drug screen [37] should be highly discouraged. Substance use disorders are increasingly recognized as a public health issue and not one of criminal justice, and withholding social support (including treatment) from those with the highest need will contribute to increasing social inequalities.

This study is not without limitations. The cross-sectional design limits inferences, as temporality is impossible to establish. For instance, the question of whether unemployment causes NMUPO and NMUPS or vice versa remains unknown. To demonstrate any changes over time in nonmedical prescription drug use patterns, longitudinal data would be required. However, this study does provide valuable information on the prevalence of NMUPS an NMUPO across different groups of adults of working age in a nationally representative sample. These data are useful in describing how use varies across a broad social structure of our society. While the downstream social and economic costs of nonmedical prescription drug use are very apparent, the drivers of initiation in adult working populations are less than finite. The research presented in this paper informs us that regulatory and clinician-initiated prevention strategies should be tailored for the myriad of drug classes, employment groups, and other social strata, such as age groups.

\section{Conclusion}

The current research, in conjunction with the context of today's nonmedical prescription drug use epidemic, leads us to comment on two actions the public health community can take, which are separate from the regulatory and clinical suggestions described earlier. Firstly, the findings from the current study highlight the need to examine in greater detail the determinants of NMUPO and NMUPS among the part-time employed and those not in the workforce. These unique associations indicate that analyses of prescription substance use among adults should not broadly categorize employment status or prescription drugs, since significant patterns across demographic, social, and behavioral subgroups exist. Secondly, as is already being done in some communities, public health practitioners must target patient advocacy partners to address the push of stronger, more addictive medications into doctors' offices and patients' hands. A number of studies [38, 39] describe prescription opioid-related harms as being associated with highly potent oxycodone formulations, for which accessibility of market entry has been quick and aggressive. Reproaching legislative flexibility that allows pharmaceutical companies to push unnecessarily potent formulations into populations with little added medical benefit than relatively less potent formulations should be prioritized. The findings presented in the current study elucidate the 
association between employment status and NMPD, which should guide translational epidemiologists to study effective regulatory leverage points to control employment and prescription drugs to limit the problem's growth.

\section{Compliance with ethical standards}

Role of funding source The data reported herein come from the National Survey of Drug Use and Health (NSDUH) public use files and made publicly available by the Substance Abuse and Mental Health Services Administration (SAMHSA). This study is IRB exempt. Dr. Martins is currently funded by the US National Institutes of Health (NIH), National Institute of Drug Abuse (NIDAR01DA037866 and R01DA039454), the Eunice Kennedy Shriver National Institute of Child and Human Development (NICHDR01HD060072), and by a Columbia University President's Global Innovation Fund. June Kim is funded by the National Institutes of Health (NIH) National Institute of Drug Abuse (NIDA5T32DA031099-04). Mirko Savone is funded by the Valerie Fund. Luis Segura is funded by the CONACYT doctoral scholarship.

Conflict of interest Dr. Martins was a consultant for Purdue Pharma until December 2014 on secondary data analysis of data on nonmedical prescription opioid use and alcohol use unrelated to what is described in this manuscript. All other authors have no conflict of interest to declare.

\section{References}

1. Epidemic: Responding to America's Prescription Drug Abuse Crisis (2011) Executive Office of the President of the United States, Washington, D.C

2. Macrae J, Hyde PS, Slavitt A (2015) HHS launches multi-pronged effort to combat opioid abuse. HHS Blog, vol 2016. SAMHSA

3. Rudd RA, Aleshire N, Zibbell JE, Gladden RM (2016) Increases in Drug and Opioid Overdose Deaths-United States, 2000-2014. MMWR Morb Mortal Wkly Rep 64(50-51):1378-1382. doi:10. 15585/mmwr.mm6450a3

4. Goldberger B, Thogmartin J, Johnson H, Paulozzi L, Rudd R, Ibrahimova A (2011) Drug overdose deaths-Florida (2003-2009) MMWR 2011. Morb Mort Wkly Rep 60(26):869-872

5. Paulozzi LJ, Budnitz DS, Xi Y (2006) Increasing deaths from opioid analgesics in the United States. Pharmacoepidemiol Drug Saf 15(9):618-627. doi:10.1002/pds.1276

6. Fingerhut LA (2008) Increases in poisoning and MethadoneRelated Deaths: United States, 1999-2005. NCHS Health and Stats. Centers for Disease Control and Prevention

7. Drug Abuse Warning Network (2012) Highlights of the 2010 Drug Abuse Warning Network (DAWN) Findings on Drug-Related Emergency Department Visits

8. Hansen RN, Oster G, Edelsberg J, Woody GE, Sullivan SD (2011) Economic costs of nonmedical use of prescription opioids. Clin J Pain 27(3):194-202. doi:10.1097/AJP.0b013e3181ff04ca

9. Cerda M, Santaella J, Marshall BD, Kim JH, Martins SS (2015) Nonmedical prescription opioid use in childhood and early adolescence predicts transitions to heroin use in young adulthood: a National Study. J Pediatr 167(3):605-612.e1-2. doi:10.1016/j. jpeds.2015.04.071

10. McCabe SE, Schulenberg JE, O'Malley PM, Patrick ME, Kloska DD (2014) Non-medical use of prescription opioids during the transition to adulthood: a multi-cohort national longitudinal study. Addiction 109(1):102-110. doi:10.1111/add.12347

11. Martins SS, Santaella-Tenorio J, Marshall BD, Maldonado A, Cerda M (2015) Racial/ethnic differences in trends in heroin use and heroin-related risk behaviors among nonmedical prescription opioid users. Drug Alcohol Depend 151:278-283. doi:10.1016/j. drugalcdep.2015.03.020

12. Martin MJ, Martin MJ, Blozis SA, Boeninger DK, Masarik AS (2014) The timing of entry into adult roles and changes in trajectories of problem behaviors during the transition to adulthood. Dev Psychol 50(11):2473-2484. doi:10.1037/a0037950

13. Miller T, Novak SP, Galvin DM, Spicer RS, Cluff L, Kasat S (2015) School and work status, drug-free workplace protections, and prescription drug misuse among Americans ages 15-25. J Stud Alcohol Drugs 76(2):195-203

14. Smith ME, Farah MJ (2011) Are prescription stimulants "smart pills"? The epidemiology and cognitive neuroscience of prescription stimulant use by normal healthy individuals. Psychol Bull 137(5):717-741. doi:10.1037/a0023825

15. Barbaresi WJ, Colligan RC, Weaver AL, Voigt RG, Killian JM, Katusic SK (2013) Mortality, ADHD, and psychosocial adversity in adults with childhood ADHD: a prospective study. Pediatrics 131(4):637-644. doi:10.1542/peds.2012-2354

16. Henry AD, Lucca AM (2004) Facilitators and barriers to employment: the perspectives of people with psychiatric disabilities and employment service providers. Work (Reading, Mass) 22(3):169-182

17. Schwarz A (2015) Workers Seeking Productivity in a Pill Are Abusing A.D.H.D. Drugs. The New York Times

18. Results from the 2013 National Survey on Drug Use and Health: Summary of National Findings (2014). H-48. Substance Abuse and Mental Health Services Administration, Rockville, Maryland

19. Jordan BK, Karg RS, Batts KR, Epstein JF, Wiesen C (2008) A clinical validation of the National Survey on Drug Use and Health assessment of substance use disorders. Addict Behav 33(6):782-798. doi:10.1016/j.addbeh.2007.12.007

20. Results from the 2008 National Survey on Drug Use and Health: national findings (2009) H-36. Substance Abuse and Mental Health Services Administration, Rockville, Maryland

21. Widiger TA, Smith GT (1994) Substance use disorder: abuse, dependence and dyscontrol. Addiction 89(3):267-282. doi:10. 1111/j.1360-0443.1994.tb00889.x

22. Morasco BJ, Turk DC, Donovan DM, Dobscha SK (2013) Risk for prescription opioid misuse among patients with a history of substance use disorder. Drug Alcohol Depend 127(1-3):193-199. doi:10.1016/j.drugalcdep.2012.06.032

23. Price AM, Ilgen MA, Bohnert AS (2011) Prevalence and correlates of nonmedical use of prescription opioids in patients seen in a residential drug and alcohol treatment program. J Subst Abuse Treat 41(2):208-214. doi:10.1016/j.jsat.2011.02.003

24. Weyandt LL, Janusis G, Wilson KG, Verdi G, Paquin G, Lopes J, Varejao M, Dussault C (2009) nonmedical prescription stimulant use among a sample of college students: relationship with psychological variables. J Atten Disord. doi:10.1177/ 1087054709342212

25. Substance Abuse and Mental Health Services Administration (2014) 10.8 Million full-time workers have a substance use disorder. The NSDUH Report: Data Spotlight

26. Eitle D, Taylor J, Eitle TM (2010) Heavy episodic alcohol use in emerging adulthood: the role of early risk factors and young adult social roles. J Drug Issues 40(2):295-320. doi:10.1177/ 002204261004000203

27. Johnston L, O'Malley P, Bachman J, Schulenberg J, Miech R (2014) Monitoring the Future national survey results on drug use, 1975-2013: vol 2, College students and adults ages 19-55. 
Institute for Social Research, The University of Michigan, Ann Arbor, Michigan

28. Bachman JG, O'Malley PM, Johnston LD (1984) Drug use among young adults: the impacts of role status and social environment. J Pers Soc Psychol 47(3):629-645

29. Gallagher RM (2009) Pharmacological management of persistent pain in older persons. Pain Med 10(6):1062-1083. doi:10.1111/j. 1526-4637.2009.00699.x

30. Greely H (2008) Towards responsible use of cognitive-enhancing drugs by the healthy. Nature 456(7223):702-705

31. Andersen I, Brønnum-Hansen H, Kriegbaum M, Hougaard CØ, Hansen FK, Diderichsen F (2016) Increasing illness among people out of labor market-A Danish register-based study. Soc Sci Med 156:21-28. doi:10.1016/j.socscimed.2016.03.003

32. Pompili M, Innamorati M, Di Vittorio C, Baratta S (2014) Unemployment as a risk factor for completed suicide: a psychological autopsy study. Arch Suicide Res 18(2):181-192. doi:10.1080/13811118.2013.803449

33. Harvey SB, Modini M, Christensen H, Glozier N (2013) Severe mental illness and work: what can we do to maximise the employment opportunities for individuals with psychosis? Aust N Z J Psychiatry 47(5):421-424

34. Baldwin ML, Marcus SC (2014) The impact of mental and substance-use disorders on employment transitions. Health Econ 23(3):332-344. doi:10.1002/hec.2936

35. Berkman LF, Glass T (2000) Social integration, social networks, social support, and health. Soc Epidemiol 1:137-173

36. Klinenberg E (2015) Heat wave: a social autopsy of disaster in Chicago. University of Chicago Press, Chicago

37. Carpenter CS (2007) Workplace drug testing and worker drug use. Health Serv Res 42(2):795-810

38. Fischer B, Keates A, Bühringer G, Reimer J, Rehm J (2014) Nonmedical use of prescription opioids and prescription opioid-related harms: why so markedly higher in North America compared to the rest of the world? Addiction 109(2):177-181

39. Laxmaiah Manchikanti M, Bert Fellows M, Hary Ailinani M (2010) Therapeutic use, abuse, and nonmedical use of opioids: a 10-year perspective. Pain Phys 13:401-435 